\title{
USING 3D WEBGIS TO SUPPORT THE DISASTER SIMULATION, MANAGEMENT AND ANALYSIS - EXAMPLES OF TSUNAMI AND FLOOD
}

\author{
J-H. Hong ${ }^{1}$, C-Y. Tsai ${ }^{2, *}$ \\ ${ }^{1}$ Department of Geomatics, National Cheng Kung University, Taiwan, junghong@ mail.ncku.edu.tw \\ ${ }^{2}$ Graduate Student, Department of Geomatics, National Cheng Kung University, Taiwan, p66094044@gs.ncku.edu.tw
}

\section{Commission IV}

KEY WORDS: 3D Building, CityGML, Tsunami, Flooding, Disaster Management, Web GIS

\begin{abstract}
:
In recent year, 3D geographic information system (GIS) has been receiving great attention from a variety of domains, but many 3D GIS applications are nevertheless restricted to visualization purposes only. One major reason for such limitation is the lack of formalized and comprehensive mechanism for the management and analysis of feature-based 3D geographic data. From a 3D GIS perspective, this study proposes a web-based system facilitating the simulation, analysis and visualization of disaster caused by tsunami and floods because these two types of hazard are highly related to the height and depth aspects. The core of the proposed system is the hierarchical 3D building framework capable of modelling different levels of building units and linking domain data via standardized identifiers in an integrated fashion. The system is designed as a decision support system that allows users to import real or simulated disaster scenarios and automatically response with the visualized damage assessment information. The 3D illustration not only provides a direct and intuitive interface for decision makers to visually inspect the outcomes at different levels of granularity, the symbology of 3D buildings can be also flexibly customized to highlight the impacts according to the perspective of the chosen applications. Quantitative vulnerability indexes are dynamically updated according to the timeline of the imported disasters to aid the decision of emergency response actions. The evacuation plan also can additionally consider the 3D aspects, such that citizens will be provided with information about nearby safe places (e.g., tall buildings or high hills) to reduce the loss of lives.
\end{abstract}

\section{INTRODUCTION}

In 2011, the Tohoku earthquake caused massive economic loss and humanitarian crisis to Japan. Especially the tsunami came after the earthquake forces a large number of people taking immediate actions to evacuate to safe places. Unfortunately, there were still more than 18000 people lost their lives or were missing. Unaware of the coming threat and no prompt instruction for evacuation certainly contribute to this tragedy. In addition to tsunami, flood is the most frequently hazard in many countries. Often caused by heavy rainfall or typhoon, flood brings tremendous damages to the buildings and facilities, and even force people to temporarily evacuate to shelters for better protection. Both types of hazard must take the aspects of height and depth, i.e., 3D perspective, into consideration. Some recent examples are further discussed as follows:

1. Kumamoto, the third metropolitan in Kyushu, Japan, received continuously heavy rainfall in the summer, 2020. The Geospatial Information Authority of Japan (GSI) conducted flooding simulation with digital terrain model and photos from social media, and found that the depth of flood reaches 5 meters at JR Hitoyoshi station and more than 8 meters at Kumamura area (Japan Meteorological Agency, 2020).

2. In 2020, China was hit by floods due to continuous heavy rain, the depth of flood reaches 4 meters on the road of a small town in Guizhou. It is the most serious flooding disaster for this town in the past fifty years (Everington, 2020).

3. Because tsunami did not strike Ishinomaki in the last one hundred years, a bridge with the height of 6 meters above mean sea level was chosen as the shelter for students. This decision eventually caused 74 deaths. The first floor of a hospital in Onagawa was flooded and 12 people died because its altitude was only 16 meters above the mean sea level (Fire and Disaster Agency (Japan), 2014).

The above tragic incidents show how important the height information is to the task of disaster management, especially for assessing the real-world situations, making correct evacuation decisions and even choosing the locations of the shelters. Failures to precisely address the height issue and appropriately modelling the 3D phenomena in reality impede the correct decision making. As the damages caused by tsunami and floods is largely related to the depth of flood at different places, it is required for the process of mitigation and preparedness to simulate the flooding disaster potential, locate the safe places (using 3D data) and draft evacuate plan accordingly. During emergency response, correct and in-time decisions have dominant influence on the loss of lives and damages of economics. Decision makers usually have to work against the clock. They tend to speed up execution of their decision strategies or switch to simpler strategies when the time is limited (Ordóñez, \& Benson III, 1997). A knowledge-based system capable of comprehensively considering all the aspects about disaster data and operations, as well as precisely provide simulation and prediction capability will tremendously improve the process of all the four phases of disaster management, namely, mitigation, preparedness, response, and recovery. We proposed a GIS-based approach that integrates the technology of Web, 3D GIS, visualization and decision making in this study, so as to provide a new insight to the mechanism of disaster management.

\footnotetext{
* Corresponding author
} 
In recent years, Geographic information system has become an indispensable component in governments' information infrastructure. As disaster data can be characterized from the perspectives of $5 \mathrm{~W} 1 \mathrm{H}$ (where, when, what, who, why and how), GIS becomes a perfect candidate to model and monitor the dynamically changing phenomena before, during and after hazards strike. By incorporating formalized domain models of hazards, GIS-based system can simulate the threats of hazards and generate accurate assessment of damages for further evaluation. Furthermore, the distinct advantages of visual presentation of the geographic distribution of disaster information enables the effective data management and correct policy making from a spatio-temporal perspective (BazanKrzywoszańska et al., 2019). For example, the Federal Emergency Management Agency (FEMA) in United States uses GIS technology to dynamically update flood maps and improve the making of the disaster mitigation strategies (FEMA, 2020). The US National Oceanic and Atmospheric Administration (NOAA) applies the well-known model, SLOSH, to predict highrisk flooding locations, and improve storm disaster preparedness (NOAA, 2020).

3D city models have been widely used by the fields of city and regional marketing, tourism, telematics, civil protection, real estate management and facility management (Altmaier, \& Kolbe, 2003). A distinguished property of 3D GIS is its visualization capabilities provide a far more realistic and intuitive reading than that of the traditional 2D map. Typical 3D city model is composed of various themes of city phenomena, e.g., terrain, buildings, roads, waterbody, vegetation, modelled with 3D geometric primitives. Among the proposed themes, 3D building is often regarded as an essential phenomenon of real-world representation (Billen, \& Zlatanova, 2003) because it not only describes the appearance of the city, but also serves as the major location reference of human beings' activities (e.g., residence and working places). The integration of $3 \mathrm{D}$ city models and crossdomain information provides a comprehensive basis for analyst to explore how the ecosystem of the city works. As the cost for creating $3 \mathrm{D}$ data is often extremely high, the development of $3 \mathrm{D}$ SDI is necessary to facilitate the successful sharing and interoperable use of cross-domain 3D GIS data.

Spatial Decision Support Systems (SDSS) combine the spatial and non-spatial data with the analysis and visualization functions of GIS, the decision-making models of specific domains, the evaluation of solution alternatives and the assessment of their trade-offs (Keenan, \& Jankowski, 2019). The major merit of SDSS is its capability to spatially analyse the given situations and evaluate different alternatives. For example, the emergency response plan is designed according to the simulation of various scales of coming threats. According to Amirebrahimi et al. (2015), the higher the Levels of Detail (LoD) of 3D building is, the accurate the analysis of property loss is. As the success of decision-making systems heavily rely on the quality of data and the formalization of domain knowledge, the realistic representation of 3D GIS data can surely provide significant advantages over the counterpart of 2D presentation (Van Ackere et al, 2016). In order to make the applications of GIS be most convenient and mobile, through the combination of Internet and GIS has become the rudimentary information infrastructure all over the world, which also makes it the most crucial method to deliver GIS information (Singh, \& Grag, 2016).

In this study, we propose to develop a web-based disaster management system using 3D GIS technology. This system intends to model selected phenomena in a 3D fashion, simulate disaster scenarios according users' given parameters and visually present analysed outcomes as reference for decision making. Such decision-making systems can be used for assessing evacuation plans in the mitigation phase and transforming the results into an operational procedure during the emergence response process.

\section{METHODOLOGY}

A web-based prototype system of decision-making is proposed in this study to demonstrate how 3D perspectives can be introduced in the task of disaster management. Geospatial technology is used for the simulation, analysis, and visualization of how tsunami and floods may impact the test sites. Three major design strategies are introduced. The first strategy is to design a multi-level hierarchical framework of 3D building units, such that the management, analysis, and visualization can be subject to the chosen level, namely, building, storey, and household, according to the tasks at hands. This provides a flexible operation module to meet the various demands of simulated scenarios. The second strategy is to develop a cross-domain information linkage mechanism, such that the information from other sources can be integrated to its corresponding level of 3D building units on the basis of individual features. This linkage capability tremendously expands the scope of damage analysis from the spatial perspective, especially for those resources that do not have direct geospatial reference. Finally, the system is designed with built-in capabilities for visually and dynamically presenting property damages and lives loss information to support smart decision making, both in the format of maps and dashboard. One basic requirement for the smart decision support system is to create and assess the loss and analyse evacuation actions according to usercustomized scenarios. For example, with the given scenarios, the smart decision support system must be able to identify safe places for evacuation, determine if the capacity is enough for the evacuated citizens and instruct their moving actions. This capability is useful in both the phase of mitigation (evaluation of evacuation plan) and response (suggestion of evacuation actions).

\subsection{Hierarchy of 3D Building Modelling}

$3 \mathrm{D}$ building is considered as an essential component of the 3D city model. The 3D presentation of building is especially useful for disaster that require height information. From a physical perspective, a single building may be subdivided into one or serval storeys, an individual storey can be related to one or further subdivided into serval households. The hierarchical design of building units, namely, building, storey and household, have their respective attributes, so that the analysis can be subjected to any chosen levels. After the relationships between these classes are formally defined, more information can be generated accordingly. Domain-specific attributes (e.g., population) for urban objects can then be linked to the corresponding levels of 3D building units via unique identifiers. Some attribute information of hierarchical 3D building units is shown in Table 1. Another concern for using $3 \mathrm{D}$ data in disaster management is to choose the right LoD of urban objects according to application needs (Kemec et al, 2012). As every LoD has its own distinguishing specification, the same building may be modelled differently in different LoDs. This design enables the multiple representation of city phenomena such that the spatial analysis and visualization can be conducted in a flexible way. A lot of researches have been dedicated to expanding the use of indoor information, the socalled LoD4 data in CityGML (Tang et al, 2018).

Figure 1 shows an example of the hierarchical building-storeyhousehold representations in this study. Each level of 3D building 
data has its own geometry and attribute information. The geometry of the chosen levels of building units are defined by features recorded by multipatch of 3D coordinates. Different levels of 3D building units are modelled separately and linked via additional relationships between their respective IDs.

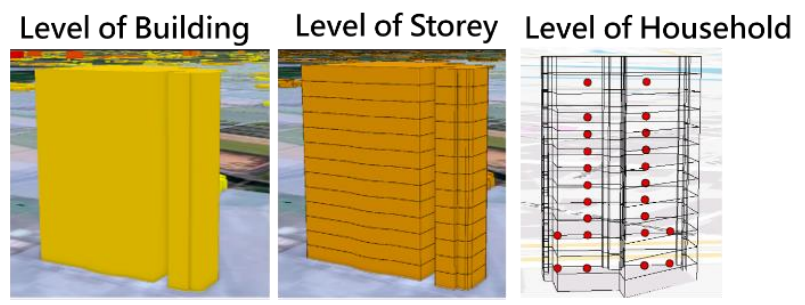

Figure 1. Building, storey, and household of hierarchy representation

To ensure the correct linking between different levels of 3D building units, every building unit is assigned a unique identifier. The identifier of building level is composed of the code of township or district and a serial number. The identifier of the storey level is then extended from the Building ID by appending a number indicating its located storey. Finally, the identifier of the household level is further extended from the storey ID by appending a serial number of households. Table 2 shows an example of the identifiers for each level of the building units. The first part of identification number " 1000209 " is the code of Wujie township. This design ensures all the building units, regardless of its level, can be uniquely identified and linked to both data from other domains and the attribute information relationship of the others level of hierarchy. This implies if detailed level of domain data is available, data referred to lower level of building units can be generated via aggregation or summation operations. Therefore, the golden rule is to encourage stakeholders to provide data at higher levels of detail (e.g., analysis based on household instead of buildings)

\begin{tabular}{|c|c|}
\hline Attribute Information & Description \\
\hline Township / District code & $\begin{array}{l}\text { Identification number of } \\
\text { township / districts }\end{array}$ \\
\hline $\begin{array}{l}\text { Building ID / Floor ID / } \\
\text { Household ID }\end{array}$ & $\begin{array}{l}\text { Unique identification number } \\
\text { of building / storey / } \\
\text { households }\end{array}$ \\
\hline Address & $\begin{array}{l}\text { The address of 3D building / } \\
\text { storey / households }\end{array}$ \\
\hline Total_Floors & $\begin{array}{l}\text { Total number of storeys } \\
\text { (building level has this } \\
\text { attribute.) }\end{array}$ \\
\hline Nunber_Floor & $\begin{array}{l}\text { The number of located floor } \\
\text { (storey level has this attribute.) }\end{array}$ \\
\hline Depth & Depth of floods \\
\hline Infrastructure & $\begin{array}{l}\text { The record of whether the } \\
\text { location is shelter, school, } \\
\text { nursing home or not. }\end{array}$ \\
\hline Total_population & \\
\hline $\begin{array}{l}\text { building / storey / } \\
\text { households }\end{array}$ & The number of total people \\
\hline $\begin{array}{l}\text { Population_of_Aged_0-14 } \\
\text { in building / storey / } \\
\text { households }\end{array}$ & $\begin{array}{l}\text { The number of people aged } 0 \text { - } \\
14\end{array}$ \\
\hline
\end{tabular}

\begin{tabular}{l|l}
$\begin{array}{l}\text { Population_of_Aged_15-64 } \\
\text { in building / storey / } \\
\text { households }\end{array}$ & $\begin{array}{l}\text { The number of people aged } \\
\text { Population_of_Aged_65 up } \\
\text { in building / storey / } \\
\text { households }\end{array}$ \\
$\begin{array}{l}\text { The number of people aged 65 } \\
\text { up }\end{array}$ \\
$\begin{array}{l}\text { The avacity } \\
\text { number of populations }\end{array}$
\end{tabular}

Table 1. Attribute information of hierarchy representation

From the perspective of spatial data infrastructure, different domain data should be created and maintained by respective agencies to ensure the quality and integrity of the distributed data. For example, the nation-wide building data shall be maintained and distributed by surveying agencies and the population data should be distributed by the census bureau. As the applications of disaster management often require a variety of themes of data, it is advantageous for domain users to acknowledge the availability of 3D buildings and unique identifiers from authorized organization (e.g., surveying agencies), and adopt the same system of identifiers in their datasets. The lack of consensus agreement about the identifiers may impede and restrict the successful links between data from different sources.

\subsection{Links to Domain Data}

The design of semantic-enriched 3D building representation includes not only essential information about the buildings (e.g. number of storeys), but also cross-domain information (e.g., the disaster potential and population data). For example, the number of elder and disable population for individual building, storey or household can be linked from the census data, such that whenever a building is determined to have risk of flooding, the number of populations with high priority of evacuation can be easily calculated and visually presented in the scene interface. As long as the linking relationships can be established via common identifiers or the mapping of domain-specific identifiers, the scope of analysis can be flexibly expanded without any limitation.

\begin{tabular}{|l|l|}
\hline Level of Hierarchy & \multicolumn{1}{|c|}{ Unique Identification Number } \\
\hline Building ID & $\begin{array}{l}1000209-2444 \text { (It means 2444 } \\
\text { building in the township) } \\
\text { Floor ID }\end{array}$ \\
Household ID & $\begin{array}{l}\text { storey located on 3 } \\
1000209-2444-3-2 \text { (It means } \\
\text { household in the storey) }\end{array}$ \\
\hline
\end{tabular}

Table 2. Unique identification number of hierarchy representation

Based on the links between different domains, Figure 2 illustrates the concept of the proposed system. Various domains of data are designed and linked via common identifiers. The 3D building framework serves as the core of the 3D data in this study because it provides the necessary geometry and essential attribute information, as well as the identifier information to make the links to other sources of data possible. 


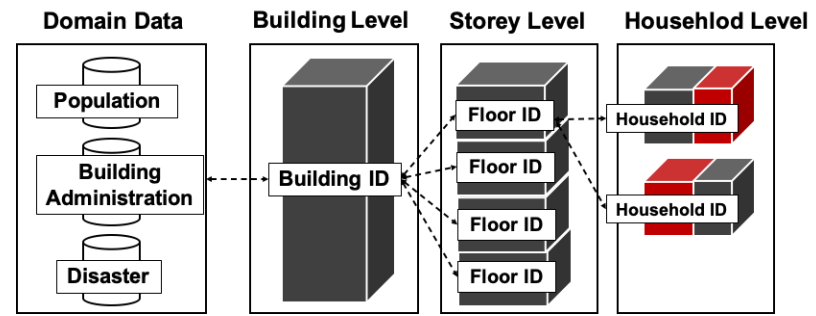

Figure 2. Link of domain data and 3D building

The cost to create and maintain a complete hierarchy of featurebased 3D building units is absolutely overwhelming. Sometimes only certain levels of 3D building units are available, hence abstract representations are used instead. For example, Figure 3 shows the street address data is represented by point features located in the space of each households. This will limit the scope of $3 \mathrm{D}$ analysis at the household level, but as long as the relationship between storey and household can be successfully established, the analysis at the storey level can still be successfully conducted. According to Kemec et al (2010), the disaster information can be divided into real-time, near real-time and high-resolution disaster information. The high-resolution disaster information (e.g. disaster potential data) is the analysis of historical disaster information for the prediction, mitigation, and preparedness of disaster. It is necessary for decision makers to use effective tool to assess the evacuation plan and simulate different scenarios before the disaster occurs.

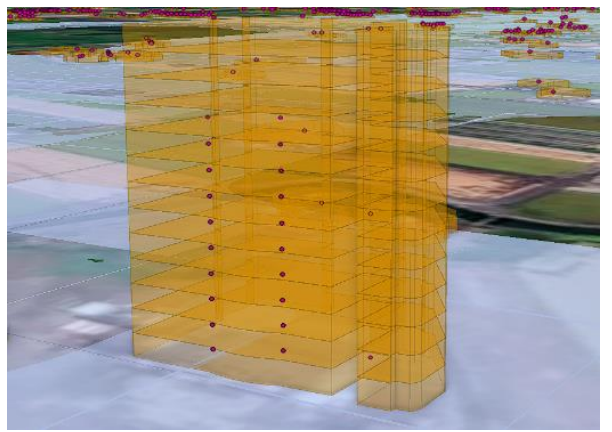

Figure 3. Household of hierarchy representation

\subsection{Smart Decision Support by Widget and Visualization}

The GIS-based decision support system consists of disaster condition setting, visualization of 3D data, Web GIS platform and disaster loss analysis. In addition to the advantages that users can remotely access the WebGIS system from anywhere, the use of Web GIS can also quickly convey messages, condense complex information, engage people in environmental change issue and motivate personal actions (Van Ackere et al, 2016). To suffice the needs of various requirement, the design adopts an All-In-One strategy where all the user interaction and visualization are integrated in the same interface. Figure 4 illustrates the flowchart of the proposed system. The details of each components and their functions are further discussed below:

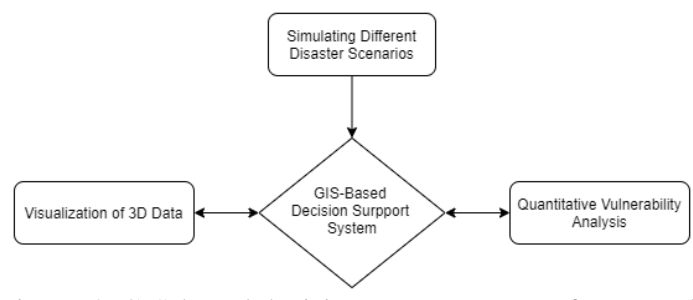

Figure 4. GIS-based decision support system framework
1. The component of disaster scenarios is designed to allow decision makers to design customized scenarios for disaster analysis, meaning the scenarios can be based on the tsunami or flood potential data or parameters issued by operators.

2. The 3D visualization enables visual inspection of the terrain, the hierarchical 3D representation of building units and the depth of floods. Furthermore, it provides the decision makers a direct and intuitive interface with both 3D map interface and reports of analysed outcomes.

3. The variety of disaster loss analysis is illustrated by texts and statistical charts according the specified parameters of hazard. The reported information is synchronously updated with the changes of parameters, so that decision makers can visually inspect the impacts by freely adjusting the parameters.

4. Based on the building units, cross-domain integration and synchronous operational mechanism, the proposed system can provide decision makers a clear and objective references for evaluating the threats from tsunami and floods.

\section{IMPLEMENTATION}

The township of Wujie in Yilan country, Taiwan was chosen as the test site because Wujie is one of coastal area in Taiwan that receives the highest impact in the simulated tsunami potential analysis by the National Science and Technology Center for Disaster Reduction (NCDR) in Taiwan. It is estimated that half of the area in Wujie has the tsunami flooding potential and the flood depth of one quarter of the area will reach 1 meter.

Four types of geospatial data are used in this study shown in Table 3, namely, Digital Terrain Model (DTM), 3D buildings, 3D roads, and raster data of disaster potential. The $20 \mathrm{~m} \times 20 \mathrm{~m}$ DTM data is obtained from the open data provided by the Ministry of Interior. The 3D buildings data of LOD1 is created from the building layers of the topographic map data. The street address data is included as the essential information of households. Since the population data is also recorded on the basis of street address, it can hence be linked to the entire hierarchy of building units via the standardized address information. For example, Figure 5 shows after the relationship between a single building and its corresponding storeys can be established via identifiers, the attribute information of this building can be queried and presented to users. As discussed in section 1, to reduce the loss of lives is always the highest priority in any disaster management task, so the population data is subdivided into three age groups: youth $(0<$ age $<14)$, adult $(15<$ age <64) and elder (age>65). 3D roads data is used for the network analysis module to find the best route for citizens to evacuate to safe places (i.e., places not threaten by the floods). The disaster potential data is used to calculate the predicted damages (e.g. overflowing area and the impacted number of populations) and visually present the degree of impacts at different places. To visualize and create 3D phenomenon, the 2D data used in this study are clamped onto the terrain model and extruded by the elevation information to present the real topography, spatial distributions, and photorealistic scenes on 3D GIS platform. Figure 6 shows the pre-processing workflow of all data used in proposed system.

\begin{tabular}{|l|l|}
\hline Class & \multicolumn{1}{|c|}{ Data } \\
\hline Terrain & $\begin{array}{l}\text { DTM of Wujie township with } \\
\text { 20mX20m resolution }\end{array}$ \\
\hline
\end{tabular}




\begin{tabular}{|c|c|}
\hline Disaster Potential & $\begin{array}{l}\text { Tsunami potential map in Wujie } \\
\text { Flooding potential (rainfall of } 650 \mathrm{~mm} \\
\text { in } 24 \text { hours) map in Wujie }\end{array}$ \\
\hline $\begin{array}{l}\text { Objects clamp on } \\
\text { the ground }\end{array}$ & Network of road data \\
\hline $\begin{array}{l}\text { Objects above the } \\
\text { ground }\end{array}$ & $\begin{array}{l}\text { Building / Storey / Household of } \\
\text { hierarchical building units } \\
\text { Address data (point feature) }\end{array}$ \\
\hline Population & $\begin{array}{l}\text { Populations of total / aged 0-14 / aged } \\
15-64 \text { / aged } 65 \text { up }\end{array}$ \\
\hline
\end{tabular}

Table 3. Datasets used in this study

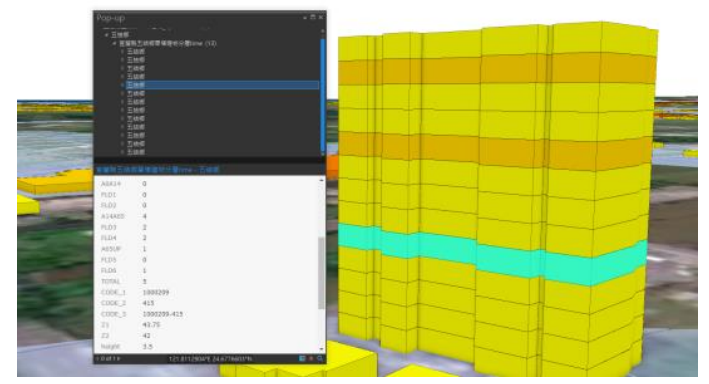

Figure 5. Attribute information relationship of hierarchy representation

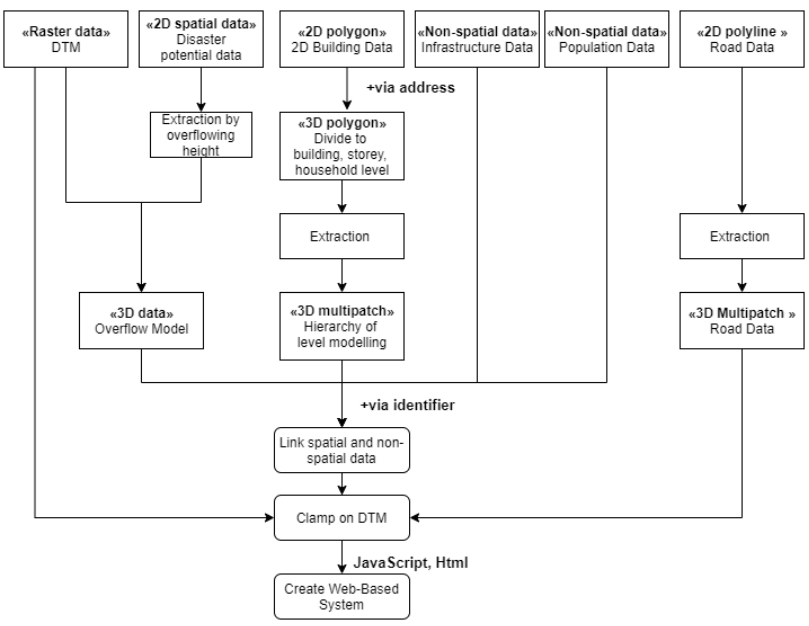

Figure 6. Data pre-processing flowchart

\section{TEST ANALYSIS}

The proposed approach has four key characteristics. First of all, the visualization mechanism of the hierarchical representation of $3 \mathrm{D}$ building units provide decision makers a more intuitive and flexible visual interface to inspect the impacts of disaster, as they can freely switch between different levels of 3D building units to evaluate the overall damage status. Secondly, the vertical information of 3D features provides a new insight to the evacuation procedure. The hierarchical representation and vertical property help searching for safe buildings and storeys that can be used for evacuation. These buildings and storeys are regarded as the "high points shelter" to suffice the needs for regional evacuation. Thirdly, the simulation of tsunami considers the temporal aspect where the threats at different time can be analysed and presented. The final breakthrough is the spatial decision support system for disaster management on the web 3D GIS platform. The platform is implemented with ArcGIS Portal and ArcGIS API for JavaScript 4.15 on the basis of 3D web scene. Figure 7 shows the workflows of the proposed system. Major implementation strategies are further discussed as follows:
1. When the threat of hazards approaches, the decision makers can select cross-domain data they wish to link for data pre-processing. For example, the land use data may be used for calculating the predicted agriculture and economic loss, while the nursing home data can be used to assess the number of elder or disable citizens that need to be evacuated.

2. Decision makers can freely simulate disaster scenarios by specifying the parameters of flooding depth and threshold values.

3. Based on the specified scenarios, the system automatically executes the built-in 3D geoprocessing procedure for generating the disaster assessment outcomes. For example, the threat to each building is calculated according to the depth of floods, number of elder populations and number of floors.

4. Based on the assessment on individual buildings, the proposed system calculates and analyses the disaster loss indexes, such as overflowing area, trapped population and affected buildings and storeys.

5. After calculating the infrastructure loss, impacted buildings, storeys and population, the outcome is visually presented to the decision makers on the basis of the 3D building units. Different strategies are designed to visually present the "differences" of selected themes of analysis. For example, the visual variable of "hue" is used for highlight the nominal difference (e.g., buildings impacted by flood or not). The visual variable of "value" or "chroma" are used to present the ratio difference (e.g., the number of elder citizens in a building) using a series of graduated colours. The designed mechanism is able to adapt to different application needs with correct cartographic design.

6. The web-based system enables the convenient use for decision makers from different domains. Decision makers can easily access the shared information from remote places and complete all the tasks without using any desktop GIS software.

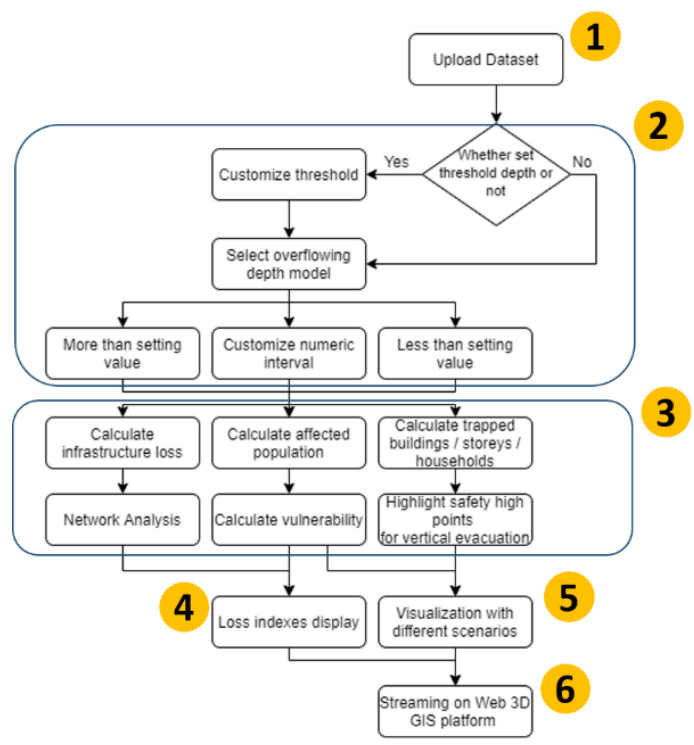

Figure 7. System operational flowchart

Figure 8 shows the interface of the proposed system. The first component is the control panel allowing users to customize the disaster scenarios. The second component is the $3 \mathrm{D}$ scene that 
illustrates the selected data themes for users to visually inspect the geographic distribution of the analysed disaster outcomes. As discussed above, the visualizations of the 3D data can be linked to data from different sources according to application needs. The third component uses a dashboard-based panel to present the loss for population. The information presented in this panel is dynamically synchronized with the control panel and the 3D map, such that the presented information will be automatically updated according to the designed scenarios.

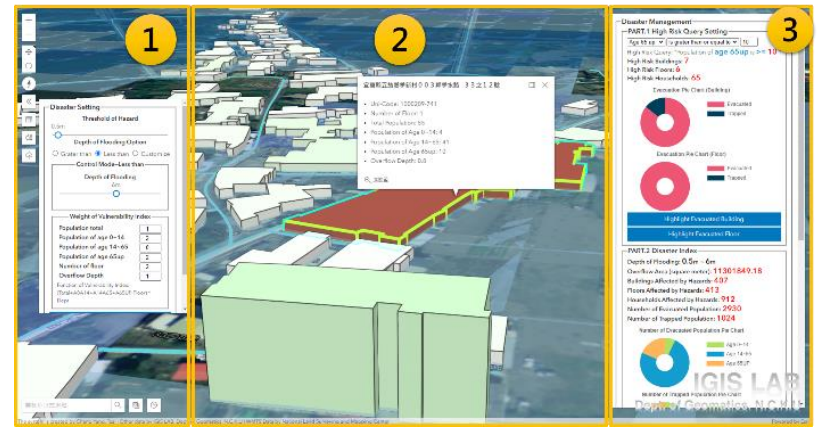

Figure 8. System components

\subsection{Analysis and Real Representation of 3D Overflowing}

The first test case is to visually present the flooding impacts in 3D scene interface. Figure 9 shows the flooded situations with different depth of flood. Buildings, storeys or households direct impacted by the tsunami or floods are represented with red colour to indicate their emergency status. It is clear the 3D illustration in Figure 9 provides a more realistic and intuitive illustration for assessing the impacts of flood than the 2D illustration.

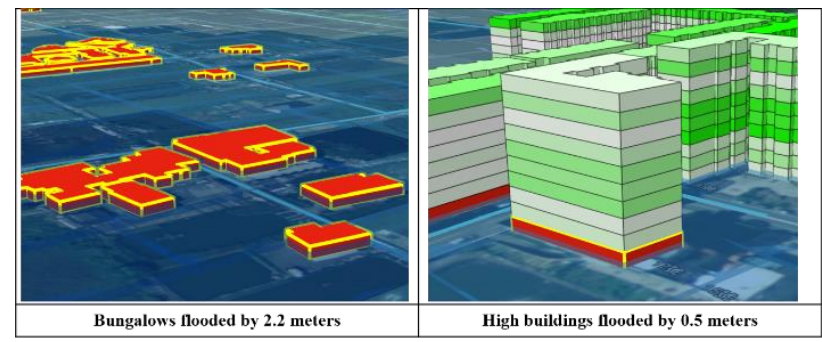

Figure 9. Comparison of different depth of flooding

\subsection{Flexible Disaster Indexes}

The second test case is to design and represent the usercustomized indexes of disaster loss of population and damage of property. Altogether 18 indexes and 5 charts are designed and grouped into three categories, namely, high risk query, disaster index and vulnerability index. Figure 10 shows the high-risk query that highlights those buildings, storey or households whose number of high-vulnerability populations exceeds the threshold values (e.g. more than 10 people whose age are more than 65 years old) to make special evacuation decisions. Finally, the vulnerability indexes are designed for assessing the overall vulnerability status. The vulnerability indexes are calculated according to populations of each interval, number of floors and flooded depth using measures of average, maximum value and standard deviation. The calculated measures of impacted population and property are shown in an integrated dashboard interface (Figure 11).

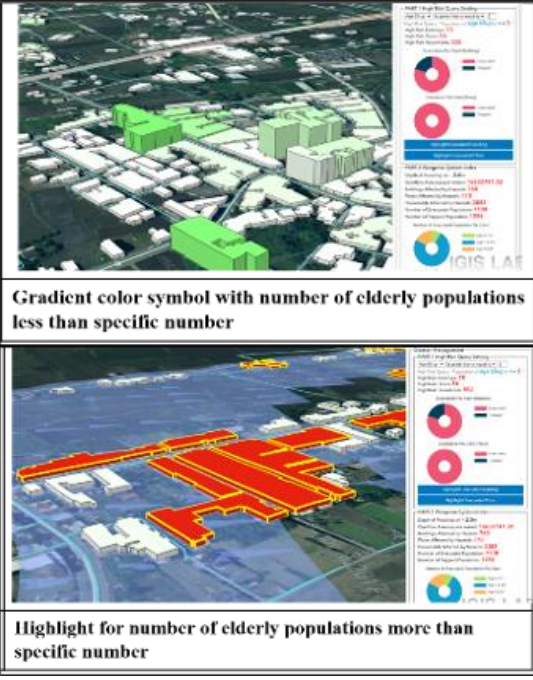

Figure 10. Visualization of number of populations aged 65 up higher than specific number

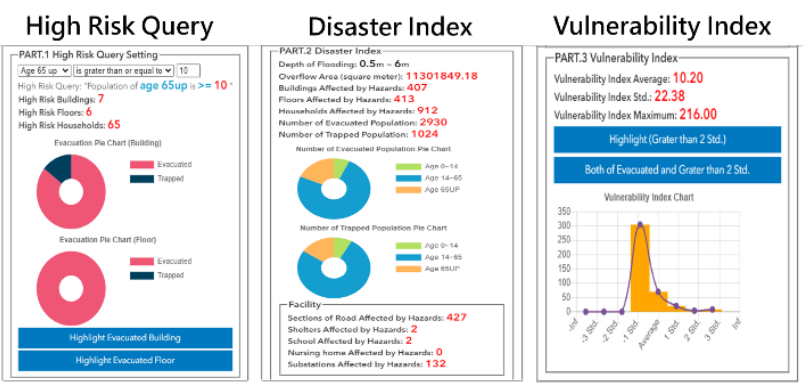

Figure 11. Disaster loss indexes

\subsection{Multi-dimensional Visualization with Different Applications and Level of Hierarchy}

The third test case demonstrates the flexible visualizations of the proposed system according to the chosen applications and level of building units. Two examples are discussed. The first is to simulate the overflowing situation and predict the loss at different time during the tsunami strikes. Unlike other disasters, time factor plays an important role in tsunami disaster. Figure 12 shows the simulated run-up of tsunami at four different time. In this simulation, the results include visualization and the number of affected populations and infrastructures, such as the shelter, school, and nursing home. After the time information is considered, the priority of evacuation can be determined accordingly.

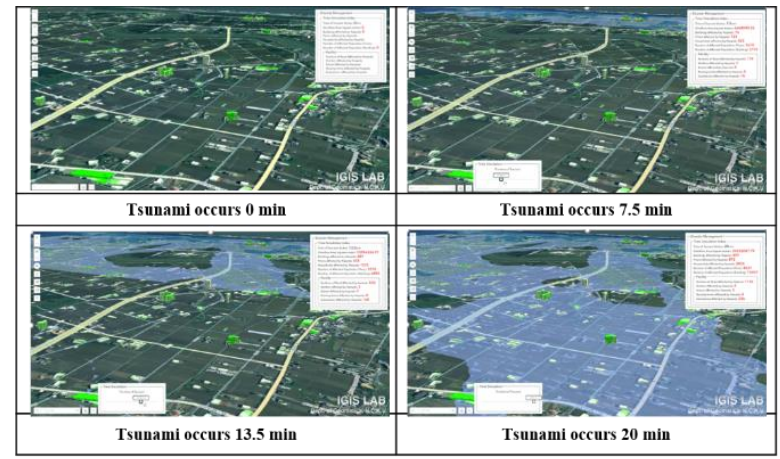

Figure 12. Tsunami run-up synchronous analysis and visualization 
The second example demonstrates the visualization according to the quantitative measure of chosen topics (e.g. available capacity). In Figure 13, two buildings with different maximum capacity for evacuation are visually presented. The capacity simulation is determined by whether the building is open to the public, the number of storey and the total floor area. The dark color illustrates higher capacity of the building, and the lighter color for lower capacity.

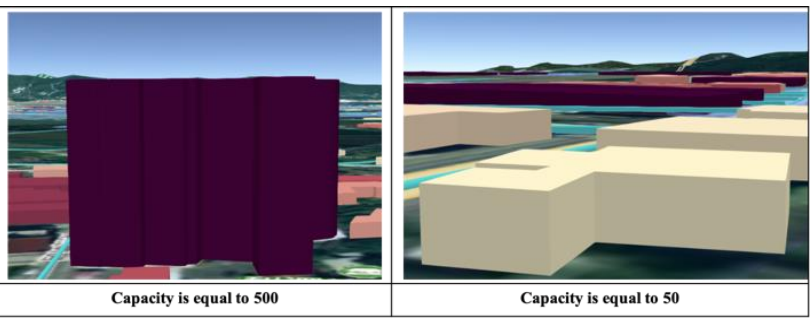

Figure 13. Visualization of capacity simulation

\subsection{Decision Making of Available Evacuation Places}

The fourth test case shows the evacuation analysis. The evacuation is determined by two major considerations, one is the travelling distance, the other is the time for evacuation. As the system can present the evacuate capacity in both the level of building and storey, decision makers can select the appropriate levels for making the evacuation decisions. The building level can be used for regional evacuation, while the storey level can be used for more precise arrangement. Figure 14 shows the result of evacuation simulation, storeys symbolized by red colour are the storeys where citizens are required to evacuate, while storeys symbolized by graduated green colours represent the different evacuation capacity at different storeys.

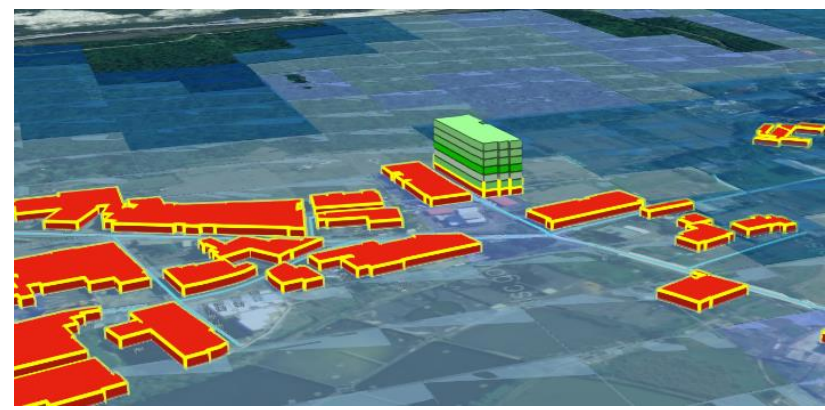

Figure 14. Visualization of high buildings for evacuation

\subsection{Evacuation Simulation}

There are two different concepts when we design the framework of evacuation. One uses network analysis to determine the shelter and evacuation routes with minimum walking time according to the current location of people. In Figure 15, the eleven circles symbols present the locations of shelters, and the square symbols present the simulated location of citizens. The line symbols of different colours show the estimated time to arrive at the shelters. From another perspective, Figure 16 uses the concept of service area to analyse the area where people can arrive the shelter within the specified time constraint. The areas illustrated with different colours present the service areas people can arrive the shelter by walking within specific time constraints. The choice of time constraints includes the time interval from 0 to 2 minutes (illustrated by the colour of green), 2 to 5 minutes (yellow), and 5 to 10 minutes (red). The combination of service area analysis and capacity evaluation can determine the high-vulnerability area outside the service area of the shelters. Special attentions must be paid to the evacuation of people living in those areas.

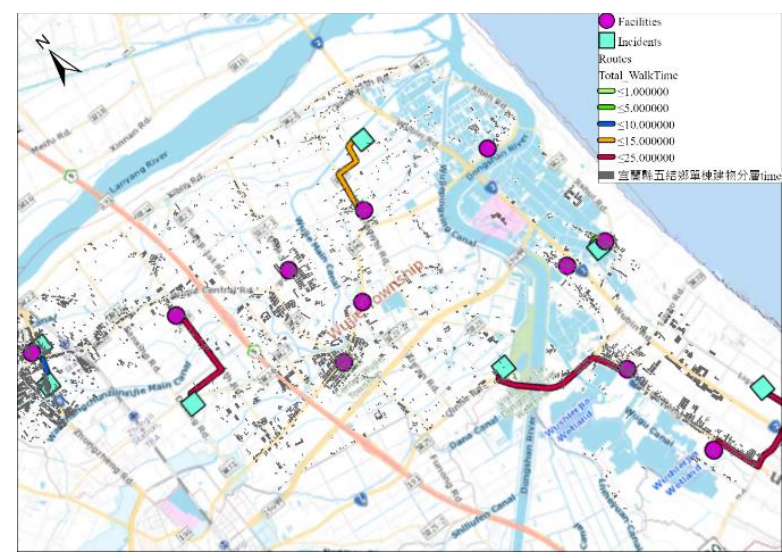

Figure 15. Evacuation visualization combining with the closest facilities analysis

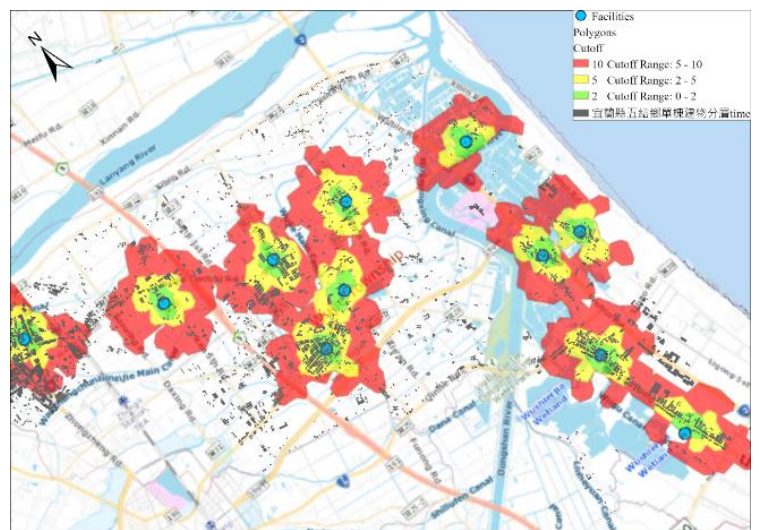

Figure 16. Evacuation visualization combining with service area analysis

\section{CONCLUSION}

With the rapid growth of 3D technology, 3D GIS has been extensively used in various applications, especially for those related to cyber city and smart city. However, many 3D GIS applications nowadays are still restricted to visualization purpose By proposing a Web-based 3D GIS system, we demonstrate how the disaster management can be improved by additionally considering the $3 \mathrm{D}$ characteristics for the threats of tsunami and floods. Three major breakthroughs are identified. First of all, the hierarchical 3D building framework provides a consistent geospatial reference for modelling the various disaster related phenomena and further enable the simulation, analysis and visualization of analyzed outcome in a 3D scene fashion. Secondly, the identifier systems across different domains enable the interoperable linkage and use of disaster related information. Finally, the integrated analysis and visualization capabilities enables decision makes to freely design analyzed scenarios and intuitively inspect the analyzed outcomes for assessing the damages and making evacuation decisions. Meanwhile, the proposed approach can not only be used in the mitigation phase, but also can be used in the emergency response phase if the flooding situation can be continuously updated. Despite the result is still preliminary, the evacuation discussed in this paper shows that the analysis can be extended to vertical dimension and illustrated according to the chosen levels of 3D buildings. To reduce the causalities, searching nearby safe places (e.g. high building and hill) with additional consideration from vertical perspective will surely provide new insights to the evacuation 
plans. There are many aspects that can be improved in the future. The hierarchy of 3D building representations can be further expanded by linking more cross-domain information (e.g. cadastral data). Secondly, the evacuation can be further combined with improved network analysis module, so that citizens can be instructed to the most appropriate buildings for evacuation. Finally, as more dynamic population data is available, the use of the location-aware service for pushing real-time instructions may calm down the anxiety emotion of the people and effectively guiding people to the most appropriate safe places.

\section{REFERENCES}

Altmaier, A., \&Kolbe, T. H., 2003. Applications and Solutions Interoperable 3D Geo-Visualization. Photogrammetric Week 2003 Conference, Stuttgart, Germany, 1-15. https://phowo.ifp.uni-

stuttgart.de/publications/phowo03/kolbe.pdf

Amirebrahimi, S., Rajbifard, A., Mendis, P., \&Ngo, T. D., 2015. A framework for micro-scale flood damage assessment and visualization for a building using BIM-GIS integration. International Journal of Digital Earth, 9(4), 363-386. doi.org/10.1080/17538947.2015.1034201

Bazan-Krzywoszańska, A., Mrówczyńska, M., \& Tront, S., 2019. GIS Technology, 3D Models and Mathematical Models as a Tool for Assessing Development Capabilities of Flood Risk Land to Make Arrangements of Municipal Planning Documents. J. Ecol. Eng., 20(1), 25-33. doi.org/10.12911/22998993/93866

Billen, R., \&Zlatanova, S., 2003. 3D spatial relationships model: a useful concept for 3D cadastre? Computers Environment and Urban Systems, 27(4), 411-425. doi.org/10.1016/S01989715(02)00040-6

Everington, K., 2020. Three Gorges Dam faces serious test as Chongqing hit by worst flooding in 80 years. Retrieved from https://www.taiwannews.com.tw/en/news/3952434

FEMA, 2020. FEMA Flood Map Service Center. Retrieved form https://msc.fema.gov/portal/home

Fire and Disaster Management Agency (Japan), 2014. 平成 23 年(2011 年)東北地方太平洋沖地震(東日本大震災)につい て . Retrieved form http://www.bousai.go.jp/2011daishinsai/pdf/torimatome201703 08.pdf

Japan Meteorological Agency, 2020. Real-time flood risk map. Retrieved from https://www.jma.go.jp/en/suigaimesh/flood.html

Keenan, P. B., \&Jankowski, P., 2019. Spatial Decision Support Systems: Three decades on. Decision Support Systems, 116, 64-76. doi.org/10.1016/j.dss.2018.10.010

Kemec, S., Duzgun, S., Zlatanova, S., Dilmen, D. I., Yalciner, A. C., 2010. Selecting 3D Visualization Models for Disaster Management: Fethiye Tsunami Inundation Case. $3^{\text {rd }}$ International Conference on Cartography and GIS, Nessebar, Bulgaria, $1-9$. https://www.academia.edu/3124310/Selecting_3D_urban_visua lisation_models_for_disaster_management_Fethiye_tsunami_in undation_case

Kemec, S., Zlatanova, S., \&Duzgum, S., 2012. A new LoD definition hierarchy for 3D city models used for natural disaster risk communication tool. $4^{\text {th }}$ International Conference on Cartography and GIS, Albena, Bulgaristan, 95-103. http://www.gdmc.nl/publications/2012/LoD_Definition_Hierarc hy_3D_City_Models.pdf

NOAA, 2020. National Storm Surge Hazard Maps - Version 2. Retrieved from https://www.nhc.noaa.gov/nationalsurge/

Ordóñez, L., \&Benson III, L., 1997. Decision under Time Pressure: How Time Constraint Affects Risky Decision Making. Organizational Behavior and Human Decision Process, 71(2), 121-140. doi.org/10.1006/obhd.1997.2717

Singh, H., \&Grag, R. D., 2016. Web 3D GIS Application for Flood Simulation and Querying Through Open Source Technology. J. Indian. Remote Sens., 44(4), 485-494. doi.org/10.1007/s12524-015-0498-5

Tang, L., Li, L., Ying, S., \&Lei, Y., 2018. A Full Level-of-Detail Specification for 3D Building Models Combining Indoor and Outdoor Scenes. ISPRS Int. J. Geo-Inf., 7(11), 419. doi.org/10.3390/ijgi7110419

Van Ackere, S., Glas, H., Beullens, J., Deruyter, G., De Wulf, A., \&De Maeyer, P., 2016. Development of a 3D dynamic flood WEB GIS visualisation tool. International Journal of Safety and Security Engineering, 6(3), 560-569. doi.org/10.2495/SAFE-V6N3-560-569 